\title{
Interference of P-REX2a may inhibit proliferation and reverse the resistance of SGC7901 cells to doxorubicin
}

\author{
YAOWEI AI ${ }^{1}$, QIAOHUI ZHOU ${ }^{1}$, LING LI ${ }^{1}$, ZHIHONG PAN $^{1}$, MINGWEN GUO ${ }^{1}$ and JINGBO HAN ${ }^{2}$ \\ ${ }^{1}$ Department of Gastroenterology, The First People's Hospital of Yichang, China Three Georges University; \\ ${ }^{2}$ Department of Anesthesiology, Ren He Hospital of Three Gorges University, Yichang, Hubei 443000, P.R. China
}

Received April 29, 2016; Accepted August 15, 2017

DOI: $10.3892 / \mathrm{ol} .2017 .7693$

\begin{abstract}
Drug resistance inhibits the efficacy of doxorubicin in gastric cancer. Phosphatidylinositol 3,4,5-trisphosphate RAC exchanger 2a (P-REX2a) activates the phosphatidylinositol-3-kinase (PI3K)/protein kinase B (Akt) signaling pathway by binding to and inactivating phosphatase and tensin homolog (PTEN), which functions as a tumor promoter in a number of types of cancer. However, there is no research concerning the association between P-REX2a expression and drug resistance in gastric cancer. In the present study, the expression of P-REX2a in clinical gastric cancer tissues was detected, and the mechanism of doxorubicin resistance in the gastric cancer cell line SGC7901 was investigated. Using reverse transcription-quantitative polymerase chain reaction and western blotting, it was demonstrated that the mRNA and protein expression of P-REX2a was increased in gastric cancer tissues. MTT assays were also used to determine proliferation, and proliferation was revealed to be reduced following transfection of P-REX2a small interfering (si)RNA. When the cells were treated with $0.3 \mu \mathrm{M}$ doxorubicin for $24 \mathrm{~h}$, the rate of apoptosis in the siRNA-transfected groups significantly increased and no marked changes in of PTEN and Akt expression were observed. By contrast, the activity of PTEN increased, and the expression of p-Akt (S473) decreased in the P-REX2a siRNA-transfected group compared with the control. The detection of PTEN enzymatic activity in the present study was based on phosphatidylinositol-3,4,5-trisphosphate. Therefore, it was concluded that P-REX2a may participate in the generation of resistance to doxorubicin in gastric cancer, and this may be associated with the upregulation of the PI3K/Akt signaling pathway via inactivation of PTEN.
\end{abstract}

Correspondence to: Dr Yaowei Ai, Department of Gastroenterology, The First People's Hospital of Yichang, China Three Georges University, 2 Jiefang Road, Yichang, Hubei 443000 , P.R. China

E-mail: aiyw2001@sohu.com

Key words: gastric cancer, phosphatidylinositol 3,4,5-trisphosphate RAC exchanger 2a, doxorubicin, drug resistance, signal pathway

\section{Introduction}

Gastric cancer is the fourth most common malignancy worldwide and has a high mortality rate (2008) (1). In 2012, there were 951,600 new cases of stomach cancer and 723,100 mortalities (2). Due to the absence of typical symptoms at an early stage of the disease, the majority of patients are diagnosed at advanced stages and lose the opportunity for surgery. Therefore, effective adjuvant chemotherapy is important in in the treatment of gastric cancer, as well as early diagnosis. However, multidrug resistance may lead to failure of chemotherapy, and the mechanism underlying this is complex (3). Drug resistance affects the long-term effectiveness of therapeutics for patients with cancer, and therefore, identifying a way to solve this problem is of great importance.

The phosphatidylinositol-3-kinase (PI3K)/protein kinase B (Akt) signaling pathway has been frequently reported to be involved in human cancer (4). Once activated, PI3K, a lipid kinase, phosphorylates phosphatidylinositol-4,5-trisphosphate $\left(\mathrm{PIP}_{2}\right)$ to form phosphatidylinositol-3, 4, 5-trisphosphate ( $\mathrm{PIP}_{3}$ ). $\mathrm{PIP}_{3}$, a secondary messenger, transfers Akt to the plasma membrane in order to be phosphorylated, activated and act on downstream signal transduction pathways, which result in cell proliferation and continuation of survival. Constitutive activation of the PI3K/Akt signaling pathway leads to maintenance of cell survival and uncontrolled proliferation, which then results in cancer. On the other hand, the PI3K/Akt signaling pathway is also activated when chemotherapy is administered, which leads to drug resistance (5). In vitro and in vivo studies have indicated that the inhibition of the PI3K/Akt signaling pathway leads to increases in sensitivity to drugs; for example, this increases the sensitivity of ovarian cancer cells to cisplatin and gastric cancer to vincristine (6,7).

The phosphatase and tensin homolog (PTEN) gene is an anti-oncogene identified in 1997, and mutations in PTEN have been identified in a number of types of cancer (8). PTEN has protein and lipid kinase activity, and dephosphorylates $\mathrm{PIP}_{3}$ through lipid kinase activity, resulting in inhibition of the activation of Akt and the promotion of anticancer effects (9). Like multiple other proteins, there are various ways of regulating the activity of PTEN, among which phosphatidylinositol 3,4,5-trisphosphate RAC exchanger 2a (P-REX2a) is a novel downregulator. P-REX2a is a RAC-GTP guanine nucleotide exchange factor with a structure similar 
to phosphatidylinositol-3,4,5-trisphosphate dependent Rac exchange factor 1 , and inhibits the activation of PTEN by binding directly with PTEN $(10,11)$. The $P$-REX2a gene is located in $8 \mathrm{q} 13.2$, and $P-R E X 2 a$ amplification is frequently observed in lung, prostatic, colon and ovarian cancer. Furthermore, P-REX2a mRNA is often amplified in lung, prostatic, glioma and pancreatic cancer, and may also participate in the tumorigenesis of breast cancer (10).

As a first-line drug in cancer therapy, resistance to doxorubicin has arisen, and this has drawn global attention. The PI3K/Akt signaling pathway may be activated and promote resistance to doxorubicin in gastric cancer cells (12). However, increased expression of PTEN may reverse this resistance $(12,13)$.

Considering that P-REX2a is able to bind with and inactivate PTEN, the expression of P-REX2a was knocked down in doxorubicin-treated SGC7901 gastric cancer cells, in order to investigate the association between P-REX2a expression and resistance to doxorubicin.

\section{Materials and methods}

Cancer tissues and cells. All 38 gastric cancer cases were obtained from the People's Hospital of Three Gorges University (Yichang, China) from February 2014 to February 2016, and included 26 males and 12 females (age range, 36-85 years; average age, 61.7). All patients received surgery without preoperative chemotherapy or immunotherapy, and diagnosis was by pathological examination for gastric adenocarcinoma. All patients provided written informed consent. Ethical approval was obtained from the Ethics Committee at the People's Hospital of Three Gorges University (Yichang, China). A total of two tissue blocks were obtained from each patient. In addition to the cancer tissues, normal tissues from the edge of the cancer tissues were obtained. Each tissue block of a thickness about $1.5 \mathrm{~mm}$ was split into three parts, with one sample fixed in $4 \%$ formaldehyde at room temperature for $24 \mathrm{~h}$ and another two samples stored at $-80^{\circ} \mathrm{C}$.

The human moderately-differentiated gastric adenocarcinoma cell line SGC7901 was used for the present study. It was purchased from the Cell Resource Center of iCell Bioscience, Inc. (Shanghai, China). The cells were cultured in a humidified incubator at $37^{\circ} \mathrm{C}$ supplemented with $5 \% \mathrm{CO}_{2}$, and the culture medium used was Dulbecco's modified Eagle's medium (DMEM; Gibco; Thermo Fisher Scientific, Inc. Inc., Waltham, MA, USA) containing 10\% fetal bovine serum (FBS; Gibco; Thermo Fisher Scientific, Inc.), $100 \mathrm{U} / \mathrm{ml}$ penicillin and $100 \mathrm{mg} / \mathrm{ml}$ streptomycin. The cells were subcultured every two days, and cells in the logarithmic growth phase were used for subsequent experiments.

Drugs and antibodies. Doxorubicin (Adriamycin) was purchased from Selleck Chemicals (Houston, TX, USA). Doxorubicin was dissolved in DMSO (Sigma-Aldrich; Merck KGaA, Darmstadt, Germany) to make a stock solution $(10 \mathrm{mmol} / \mathrm{l})$ and stored at $-20^{\circ} \mathrm{C}$. The stock solution was further diluted with culture media of DMEM containing $10 \%$ fetal bovine serum to a final working solution of $0.3 \mu \mathrm{M}$ in culture plates. Primary antibodies against PTEN (1:1,000; cat. no. CST 9188P), Akt (1:1,000; cat. no. CST 4691P), phosphorylated
(p-)Akt (S473; 1:1,000; cat. no. CST 4060P), BCL2 associated $\mathrm{X}$, apoptosis protein (Bax; 1:1,000; cat. no. CST 2772S) and B cell lymphoma-2 (Bcl-2; 1:1,000; cat. no. CST 2870P) were purchased from Cell Signaling Technology, Inc., (Danvers, MA, USA), and P-REX2a (1:1,000; cat. no. ab169027) was purchased from Abcam (Cambridge, UK). Primary antibodies against $\beta$-actin (1:200; cat. no. BM0627) and secondary antibodies, goat anti-rabbit (1:5,000; cat. no. BA1054) and goat-anti-mouse (1:5,000; cat. no. BA1051) were purchased from Wuhan Boster Biological Technology, Ltd., (Wuhan, China).

P-REX2a-small interfering (si)RNA transfection and drug treatment. A total of three P-REX2a-siRNA sequences were designed and synthesized by Suzhou GenePharma Co., Ltd. (Suzhou, China), from which two sequences were selected for the interference experiment. The sequences used were as follows: P-REX2a-Homo-883 (siRNA1) forward, 5'-GGC AUCUACAGAUGGACAUTT-3' and reverse, 5'-AUGUCC AUCUGUAGAUGCCTT-3'; P-REX2a-Homo-262 (siRNA2) forward, 5'-CAUCCUUGCAGUACAUAAATT-3' and reverse, 5'-UUUAUGUACUGCAAGGAUGTT-3' and negative control forward, 5'-UUCUCCGAACGUGUCACGUTT-3' and reverse, 5'-ACGCACGUUCGGAGAATT-3'. The cells $\left(2 \times 10^{5}\right)$ were seeded in each well of the 6 -well plate $24 \mathrm{~h}$ prior to transfection, and the original culture medium was replaced with serum-free and antibiotic-free DMEM $2 \mathrm{~h}$ prior to the transfection. The liposome-mediated method (Invitrogen; Thermo Fisher Scientific, Inc., Waltham, MA, USA), was used according to an optimized version of the supplier's (Thermo Fisher Scientific, Inc.) protocol for transfection. P-REX2a-siRNA or negative control (NC)-siRNA $(4.0 \mu \mathrm{g})$ was diluted with serum-free and antibiotic-free DMEM $250 \mu$ l, and Lipofectamine ${ }^{\circledR} 2000$ (Invitrogen; Thermo Fisher Scientific,Inc.) was also diluted with serum-free and antibiotic-free DMEM in another two tubes, then the siRNA solutions were mixed with Lipofectamine ${ }^{\circledR}$ 2000 (Invitrogen; Thermo Fisher Scientific, Inc.) solutions respectively. The solution was incubated at room temperature for $20 \mathrm{~min}$ and was then added to the cells, and the swapped serum-free and antibiotic-free DMEM with DMEM with 10\% FBS $6 \mathrm{~h}$ later. The cells were divided into four treatment groups as follows: Cells cultured under normal conditions (NM, cells were untransfected), NC-siRNA-transfected cells, and cells transfected with siRNA1 or siRNA2. The cells were treated with $0.3 \mu \mathrm{M}$ doxorubicin at $37^{\circ} \mathrm{C}$ for $24 \mathrm{~h}$ following transfection for $48 \mathrm{~h}$.

$R N A$ extraction and reverse transcription-quantitative polymerase chain reaction $(R T-q P C R)$. RT-qPCR is a common method to detect mRNA (14), the present study repeated the experiment in triplicate. Total RNA was extracted with TRIzol reagent (Invitrogen; Thermo Fisher Scientific, Inc.), and the concentration was measured with the Nanodrop 2000 spectrophotometer (NanoDrop Technologies; Thermo Fisher Scientific, Inc.). The concentration of the RNA samples was adjusted to $\sim 1 \mu \mathrm{g} / \mu \mathrm{l}$ with RNase-free water. Total RNA $(1 \mu \mathrm{g})$ was used in a $20-\mu 1$ reaction volume to perform reverse transcription with virus reverse transcriptase (Takara Bio, Inc., Otsu, Japan) according to the manufacturer's protocol. A total of $2 \mu \mathrm{l}$ reverse transcription product, $10 \mu \mathrm{l} 2 \mathrm{X}$ SYBR mixture 
(Takara Bio, Inc.), $1.6 \mu 1$ upstream and downstream primers $(10 \mu \mathrm{M})$ and $6.4 \mu \mathrm{l}$ DNase-RNase-free water was used for qPCR. The reaction was performed on the FCX96 Real-time PCR system (Bio-Rad Laboratories, Inc., Hercules, CA, USA), with 1 cycle of initial denaturation at $95^{\circ} \mathrm{C}$ for $30 \mathrm{sec}$, followed by 40 cycles of denaturation at $95^{\circ} \mathrm{C}$ for $15 \mathrm{sec}$, annealing and extension at $55^{\circ} \mathrm{C}$ for $30 \mathrm{sec}$. The fluorescence signals were captured at the extension phase of each cycle. The primer sequences were as follows: P-REX2a, forward 5'-TGGGAG GGGTCCAACATCA-3' and reverse, 5'-TCTTCAACCGTC TGTGTTTTCTT-3'; GADPH forward, 5'-GCCAAAAGG GTCATCATCTC-3' and reverse, 5'-GTAGAGGCAGGGATG ATGTTC-3'.

Western blot analysis. Every sample repeated twice. Clinical tissue samples and cells collected were incubated with radioimmunoprecipitation assay buffer (cat no. P0013B; Beyotime Institute of Biotechnology, Haimen, China) and a protease inhibitor cocktail (1:100; cat no. ST506; Beyotime Institute of Biotechnology) or phosphatase inhibitors (cat no. S1873; Beyotime Institute of Biotechnology). The protein samples were incubated on ice for $30 \mathrm{~min}$, and then centrifuged at $10,000 \mathrm{x} \mathrm{g}$ at $4^{\circ} \mathrm{C}$ for $8 \mathrm{~min}$, supernatants were then extracted and quantified using the bicinchoninic acid assay method. Equal quantities of protein samples $(\sim 60 \mu \mathrm{g})$ were electrophoresed on $10 \%$ polyacrylamide gels and electroblotted onto a polyvinylidene difluoride membrane (EMD Millipore, Billerica, MA, USA) using a semidry transfer system (Bio-Rad Laboratories, Inc.). The membrane was blocked in TBST (containing $0.05 \%$ Tween-20) with 5\% non-fat milk for $1 \mathrm{~h}$ at room temperature. Primary antibodies were diluted in TBST with 5\% non-fat milk, according the manufacturer's protocol, and the membrane was incubated with the primary antibodies overnight at $4^{\circ} \mathrm{C}$. The membranes were subsequently rinsed four times with TBST ( $5 \mathrm{~min}$ per wash), and the appropriate secondary antibodies were added for incubation at room temperature for $2 \mathrm{~h}$. Antibody staining was visualized using enhanced chemiluminescence reagents (Thermo Fisher Scientific, Inc.) and developed with exposure to X-ray films. $\beta$-actin served as an internal reference. The absorbance values were analyzed using BandScan software (version 5; Glyko Biomedical, Ltd., Toronto, ON, Canada). The ratio to reference absorbance value for each protein was measured for comparison.

MTT assay. The cells were cultured in 24-well plates at $60 \%$ confluence. The cells were divided into four groups and transfected as aforementioned. The cells were cultured for 24 , 48 or $72 \mathrm{~h}$, respectively. A total of 5 wells were used for each treatment group and $100 \mu \mathrm{l}$ MTT solution was added to each well, followed by incubation for an additional $4 \mathrm{~h}$ at $37^{\circ} \mathrm{C}$. The culture medium was subsequently removed, and 1,500 $\mu \mathrm{l}$ DMSO was added. The cells were suspended with trypsin and $200 \mu \mathrm{l}$ of the suspension was transferred to a 96 -well plate. The optical density (OD) was measured at $570 \mathrm{~nm}$ with a spectrophotometer.

Annexin V-fluorescein isothiocyanate (FITC) apoptosis assay. SGC7901 cells were cultured in 6-well plates at $60 \%$ confluence. The cells in the four treatment groups were transfected as aforementioned. The cells were treated with $0.3 \mu \mathrm{M}$ doxorubicin for $24 \mathrm{~h}$ at $37^{\circ} \mathrm{C}$ after following transfection for $48 \mathrm{~h}$. The apoptosis assay was performed according to the manufacturer's protocol, using an Annexin V-FITC and propidium iodide (PI) double staining apoptosis detection kit with flow cytometry (BD Biosciences, Franklin Lakes, USA). The protocol was as follows: Cells were collected and washed twice with PBS, centrifuged at $900 \times \mathrm{g}$ at $4^{\circ} \mathrm{C}$ for $5 \mathrm{~min}$ and resuspended with $500 \mu \mathrm{l}$ Annexin binding buffer. Cells were incubated with $5 \mu \mathrm{l}$ Annexin V-FITC solution for $5 \mathrm{~min}$ at room temperature. PI $(5 \mu \mathrm{g} / \mathrm{ml}, 5 \mu \mathrm{l})$ was added and incubated for a further $5 \mathrm{~min}$ at room temperature. Cell suspensions were analyzed with flow cytometry (FACSCalibur; CellQuest Pro software, version 5.1; BD Biosciences).

Detection of enzymatic activity of PTEN. SGC7901 cells were cultured in 6 -well plates at $60 \%$ confluence. The cells in the four treatment groups were transfected as aforementioned. The cells were treated with $0.3 \mu \mathrm{M}$ doxorubicin for $24 \mathrm{~h}$ following transfection for $48 \mathrm{~h}$. The detection of PTEN enzymatic activity was performed by cell PTEN activity colorimetric assay kit (cat. no. GMS50064.1; Shanghai Genmeds Scientific, Inc., Wilmington, DE, USA) and a spectrophotometer. According to the manufacturer's protocol, the cells were collected using phosphate-buffered saline (reagent A in the aforementioned kit) and cell scraper, and protein was obtained using a protein extraction lysate (reagent B in the kit). A standard curve was constructed, and the samples were prepared following the manufacturer's protocol. The OD was measured at $660 \mathrm{~nm}$ using a spectrophotometer and the concentration of phosphorus was calculated.

Statistical analysis. All the data are presented as the mean \pm standard deviation of at least three independent experiments. Statistical analysis was performed with SPSS 22.0 statistical software (IBM Corp., Armonk, NY, USA) using independent Student's t-tests or one-way analysis of variance followed by Fisher's least significant difference tests. Graphs were constructed using GraphPad Prism 5.0 software (GraphPad Software, Inc., La Jolla, CA, USA). P<0.05 was considered to indicate a statistically significant difference.

\section{Results}

Expression of P-REX2a in clinical gastric cancer cases. Normal and cancer tissues were separated from each case. P-REX2a mRNA expression was detected by RT-qPCR. The results revealed that the P-REX2a mRNA expression was significantly higher in the cancer tissue group compared with the normal tissue group $(\mathrm{P}<0.05$; Fig. 1A). Western blotting was performed to detect the protein expression of P-REX2a, and the results indicated that P-REX 2 a protein expression significantly increased in the cancer tissue group compared with the normal tissue group $(\mathrm{P}<0.05$; Fig. $1 \mathrm{~B})$, which was consistent with the results from RT-qPCR.

Knock down of P-REX2a inhibits the proliferation of SGC7901 cells. The expression of P-REX2a was knocked down in SGC7901 cells by RNA interference. RT-qPCR and western blotting were performed to confirm the efficiency 

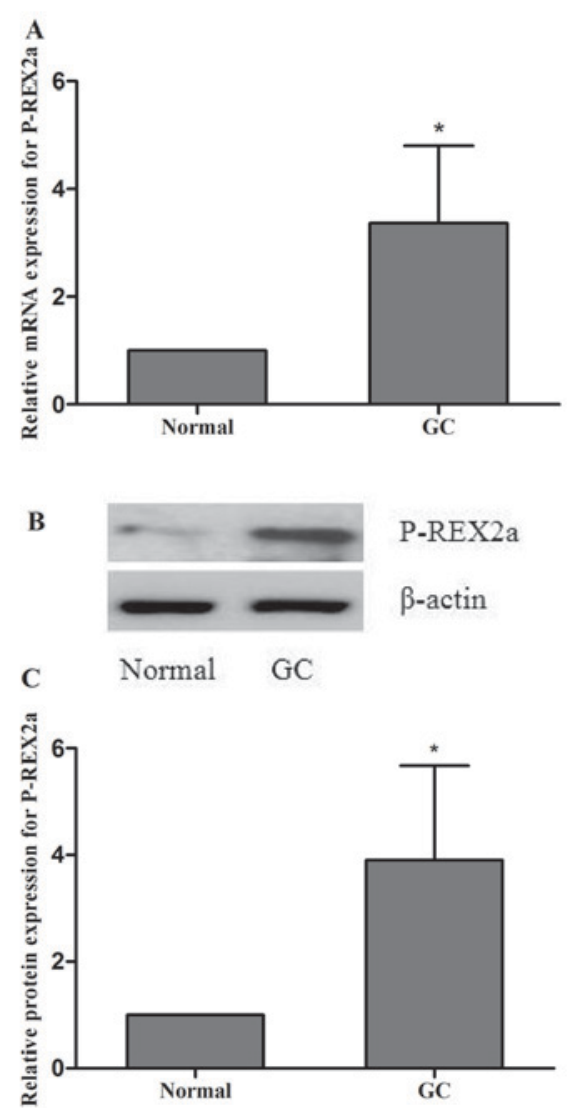

Figure 1. Relative mRNA and protein expression of P-REX2a in gastric cancer tissues. Normal tissues and gastric cancer tissues from 38 cases were subjected to (A) reverse transcription-quantitative polymerase chain reaction and (B) western blotting to detect the expression of P-REX2a. GADPH and $\beta$-actin were used as endogenous references, respectively. The normal tissue group was standardized to one as a control. Values are represented as the mean \pm standard deviation $(n=3)$. ${ }^{*} \mathrm{P}<0.05$ vs. normal. The images shown are representative images from at least three independent experiments. GC, gastric cancer; P-REX2a, phosphatidylinositol 3,4,5-trisphosphate RAC exchanger $2 \mathrm{a}$.

of P-REX2a siRNA knockdown (Fig. 2A-C). The analysis revealed that transfection with siRNA1 and siRNA2 was able to markedly inhibit P-REX2a expression in SGC7901 cells compared with the NM group, particularly transfection with siRNA2. However, no marked changes were observed in the NC group, where the cells were transfected with NC-siRNA. These results indicated that the siRNA1 and siRNA2 used in the present study were able to efficiently silence the P-REX2a expression of SGC7901 cells.

The MTT results revealed that, compared with the NM and NC group, the proliferation of SGC7901 cells in the siRNA1 and siRNA2-transfceted groups was significantly reduced $(\mathrm{P}<0.05)$, and lower activity was observed in the siRNA2-transfected group, which suggested that the inhibition of P-REX2a expression may inhibit the proliferation of SGC7901 cells. When comparing the inhibition of proliferation in the $\mathrm{NC}$ group with that of the NM group, there were no significant differences (Fig. 2D).

Knock down of P-REX2a increases the sensitivity of SGC7901 cells to doxorubicin in vitro. The cells were treated with $0.3 \mu \mathrm{M}$
A

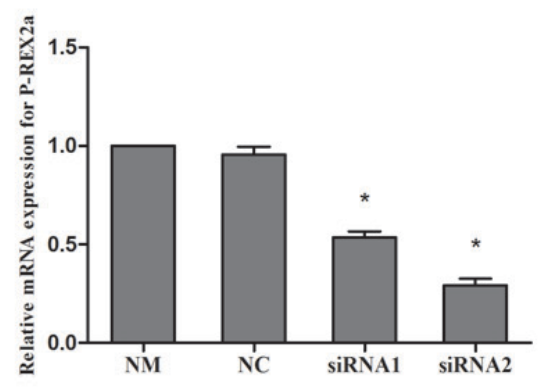

B

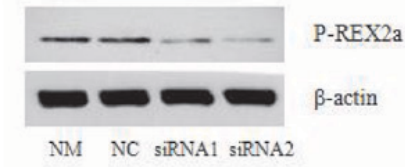

C

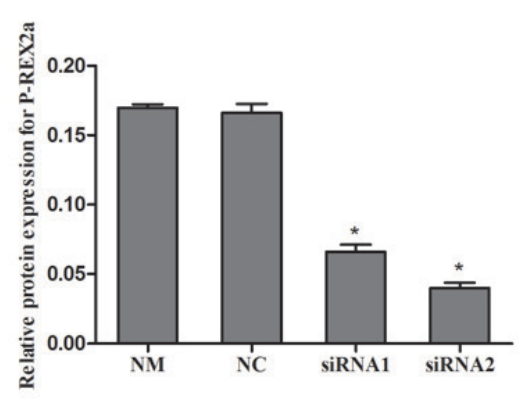

D

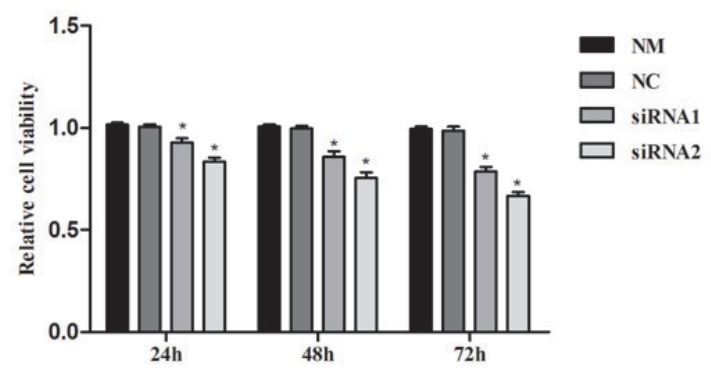

Figure 2. siRNA-mediated knockdown of P-REX2a expression. (A) Reverse transcription-quantitative polymerase chain reaction and (B) western blotting with (C) quantification were performed to analyze the levels of mRNA and protein expression following transfection for 24 and $48 \mathrm{~h}$, to confirm the knockdown efficiency. (D) Viability of SGC7901 cells was analyzed using an MTT assay. Values are represented as the mean \pm standard deviation $(n=5)$. ${ }^{*} \mathrm{P}<0.05$ vs. another siRNA group and NM group. P-REX2a, phosphatidylinositol 3,4,5-trisphosphate RAC exchanger 2a; siRNA, small-interfering RNA; NC, negative control cells; Homo-883, siRNA1; homo-262, siRNA2.

doxorubicin for another $24 \mathrm{~h}$ following transfection for $48 \mathrm{~h}$. The rate of apoptosis was determined with an Annexin V/PI double-dye apoptosis kit. The expression of $\mathrm{Bax}$ and $\mathrm{Bcl}-2$ was detected using western blotting. Compared with the NM group, there were no significant changes in the NC group. By contrast, the rate of apoptosis was significantly increased in the siRNA1 and siRNA2-transfected groups compared with the NM group $(\mathrm{P}<0.05)$. However, there were no significant changes between the siRNA1 and siRNA2-transfected groups (Fig. 3A and B). Furthermore, the expression of Bax significantly increased in the siRNA1 and siRNA2-transfected groups compared with the $\mathrm{NM}$ and $\mathrm{NC}$ groups, while the expression of $\mathrm{Bcl}-2$ was reduced $(\mathrm{P}<0.05$; Fig. $3 \mathrm{C}$ and $\mathrm{D})$. 

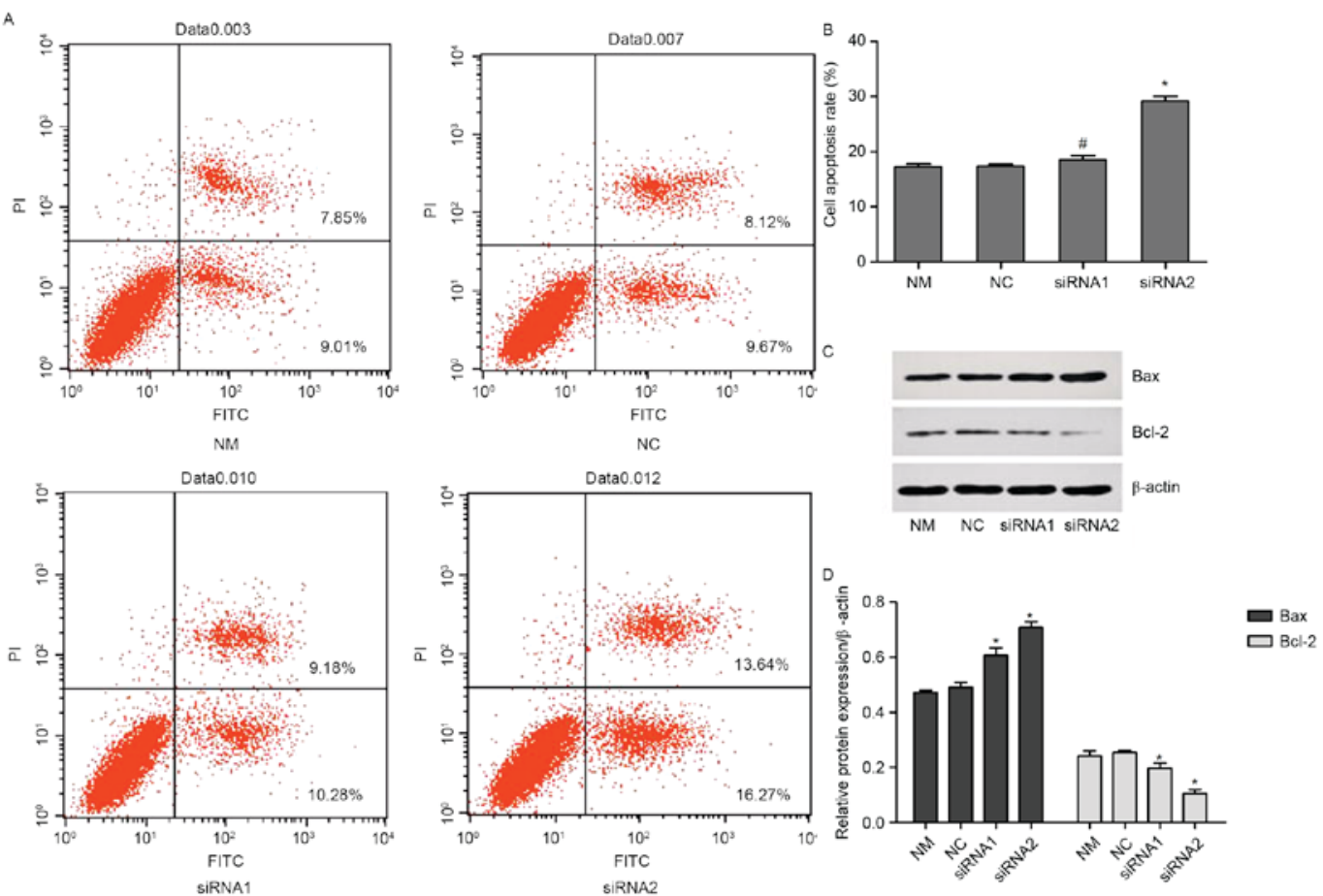

Figure 3. Rate of apoptosis of P-REX2a knocked down cells. The cells were treated with $0.3 \mu \mathrm{M}$ doxorubicin for $24 \mathrm{~h}$ and then transfected for $48 \mathrm{~h}$. (A) Apoptosis was analyzed using an Annexin V/propidium iodide double-dye apoptosis kit with (B) quantification. (C). The levels of Bax and Bcl-2 expressions were analyzed by western blotting with (D) quantification. Values are represented as the mean \pm standard deviation $(\mathrm{n}=3)$. ${ }^{*} \mathrm{P}<0.05$ vs. another siRNA group and NM group. NM, normal cultured cells; NC, negative control; Bcl-2, B-cell lymphoma 2; Bax, BCL2 associated X, apoptosis regulator; FITC, fluorescein isothiocyanate; P-REX2a, phosphatidylinositol 3,4,5-trisphosphate RAC exchanger 2a; siRNA, small-interfering RNA; NM, normal cultured cells.

Changes in the PTEN/PI3K/Akt signaling pathway. The cells were treated with $0.3 \mu \mathrm{M}$ doxorubicin for another $24 \mathrm{~h}$ following transfection for $48 \mathrm{~h}$. Western blotting was performed to detect the protein expression of PTEN, Akt and p-Akt (S473). PTEN enzymatic activity was determined using a kit with $\mathrm{PIP}_{3}$ substrate. Independent experiments were performed at least three times. The results revealed that there were no significant changes in the expression of total PTEN and total AKT between all the treatment groups, but p-Akt expression was reduced significantly in the siRNA1 and siRNA2-trasnfected groups compared with the NM and NC groups $(\mathrm{P}<0.05$; Fig. $4 \mathrm{~A}$ and $\mathrm{B})$. PTEN enzymatic activity increased significantly in the siRNA1 and siRNA2-transfected groups compared with the NM and NC groups $(\mathrm{P}<0.05$; Fig. $4 \mathrm{C})$.

\section{Discussion}

Gastric cancer is one of the most common malignant tumors worldwide. A lack of typical symptoms present at the early stage of the disease leads to patients being frequently diagnosed at advanced stages of the disease, resulting in a poor prognosis (14). Surgery is sufficient to cure a patient at the early stage of the disease. However, prognosis is dependent on the efficacy of chemotherapy in conjunction with surgery at advanced stages (15).

Chemotherapy is vital for improving the prognosis of gastric carcinoma in general. However, resistance to chemotherapeutics in gastric cancer has become more common in the clinic, lowering the efficacy of chemotherapy (16). Doxorubicin is one of the classical drugs with reported cases of resistance against
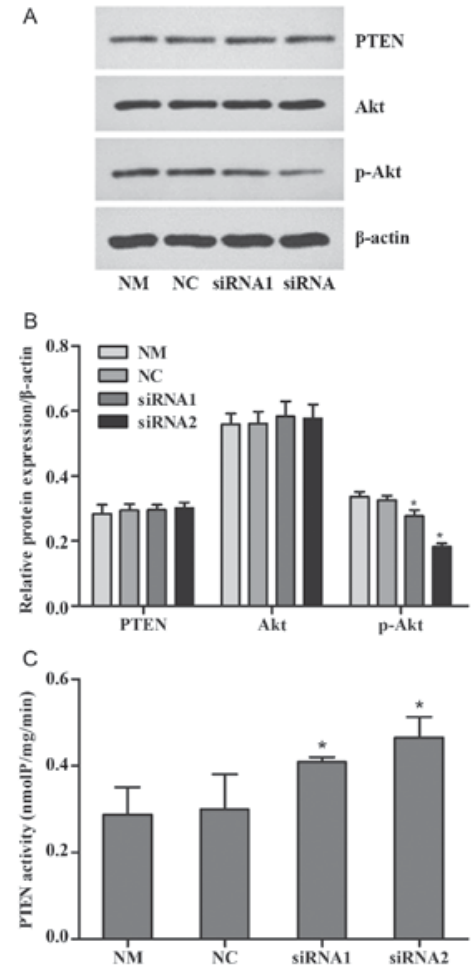

Figure 4. Levels of PTEN expression and activity. The cells were treated with $0.3 \mu \mathrm{M}$ doxorubicin for $24 \mathrm{~h}$ following transfection for $48 \mathrm{~h}$. (A) The expression of PTEN, Akt and p-Akt were detected by western blotting, with (B) quantification. (C) The enzymatic activity of PTEN was analyzed with a PIP substrate-based kit. Values are represented as the mean \pm standard deviation $(\mathrm{n}=3) .{ }^{*} \mathrm{P}<0.05$ vs. another siRNA group and NM group. $\mathrm{p}-$, phosphorylated; PIP $_{3}$, phosphatidylinositol $(3,4,5)$-trisphosphate; PTEN, phosphatase and tensin homolog; P-REX2a, RAC exchanger 2a; siRNA, small-interfering RNA; NM, normal cultured cells; NC, negative control cells. 
it. Furthermore, the PI3K/Akt signaling pathway has been implicated in the majority of cases of resistance (17-20).

P-REX2a is a guanine-nucleotide exchange factor (GEF) for Rac (21), which binds to PTEN directly and inhibits its phosphatase activity, resulting in the accumulation of $\mathrm{PIP}_{3}$ in vitro (10). The activation of $\mathrm{PI} 3 \mathrm{~K}$ results in the conversion of $\mathrm{PIP}_{2}$ into $\mathrm{PIP}_{3}$, which as a second messenger activates Akt, resulting in cell proliferation and differentiation. However, the lipid phosphatase activity of PTEN dephosphorylates PIP $_{3}$ to $\mathrm{PIP}_{2}(9)$. High expression of P-REX2a has been reported in a number of types of cancer. However, to the best of our knowledge, only one report to date has investigated P-REX2a expression in gastric cancer (22). Therefore, high expression of P-REX2a may promote cell proliferation and differentiation. In the present study, high expression of P-REX2a was confirmed in gastric cancer tissues. As $>95 \%$ cases of gastric cancer are adenocarcinomas, the SGC7901 cell line was selected for the present study. The results of the MTT assay, which assessed cell viability following the knockdown of P-REX2a, indicated that P-REX2a expression was able to promote proliferation in SGC7901 gastric cancer cells.

The PI3K/Akt signaling pathway has often been reported to be activated in chemotherapy, and inhibiting the pathway may reverse drug resistance to a certain degree, including resistance to doxorubicin in gastric cancer $(12,23,24)$. A previous study by our group on the association between doxorubicin and the $\mathrm{PI} 3 \mathrm{~K} / \mathrm{Akt}$ signaling pathway in gastric cancer has indicated that, following treatment of SGC7901 cells with $0.3 \mu \mathrm{M}$ doxorubicin and a PI3K/Akt pathway inhibitor for $24 \mathrm{~h}$, a marked increase in apoptosis and alterations in protein levels were detected (17).

Activation of the PI3K/Akt signaling pathway inhibits apoptosis, which leads to a low chemotherapy efficiency (12). P-REX2a participates in the regulation of PTEN/PI3K/Akt, which may be associated with drug resistance. In the present study, SGC7901 cells were treated with doxorubicin, and the rate of apoptosis increased when P-REX2a was knocked down. Bcl-2 and Bax are anti-apoptotic and pro-apoptotic effectors, respectively, and are important regulators in the PI3K/Akt signaling pathway (25). The expression of Bcl-2 was decreased and the expression of Bax was increased in cells transfected with P-REX2a-siRNA compared with the negative control. These results indicated that P-REX2a may promote resistance to doxorubicin in gastric cancer cells.

A previous study has reported that overexpression of PTEN in originally PTEN deficient cells may reduce phosphorylation of Akt. Phosphorylation did not markedly change if only P-REX2a was overexpressed, but Akt was activated at both S473 and T308 sites if PTEN and P-REX2a were overexpressed at the same time (10). This result indicated that $\mathrm{P}-\mathrm{REX} 2 \mathrm{a}$ regulates the PI3K/Akt signaling pathway, which is dependent on PTEN. In the present study, SGC7901 cells were treated with doxorubicin following the knockdown of P-REX2a, and the expression of PTEN, Akt, p-Akt (S473) and the lipid phosphatase activity of PTEN were detected. The results in the present study indicated that knockdown of P-REX2a was able to increase the activity of PTEN, leading to the downregulation of p-Akt during chemotherapy.

In conclusion, P-REX2a promotes resistance to doxorubicin in gastric cancer cells and may inactivate PTEN via the PTEN/PI3K/Akt signaling pathway. Therefore, it may be possible to increase the sensitivity of gastric cancer to doxorubicin by inhibiting P-REX2a in the future. At present, the research is limited, and further studies on the expression of P-REX2a in gastric cancer and confirmatory experiments in different cell lines are required.

\section{References}

1. Ferlay J, Shin HR, Bray F, Forman D, Mathers C and Parkin DM: Estimates of worldwide burden of cancer in 2008: GLOBOCAN 2008. Int J Cancer 127: 2893-2917, 2010.

2. Torre LA, Bray F, Siegel RL, Ferlay J, Lortet-Tieulent J and Jemal A: Global cancer statistics, 2012. CA Cancer J Clin 65: $87-108,2015$

3. Sun X, Bao J and Shao Y: Mathematical modeling of therapy-induced cancer drug resistance: Connecting cancer mechanisms to population survival rates. Sci Rep 6: 22498, 2016.

4. Osaki M, Oshimura M and Ito H: PI3K-Akt pathway: Its functions and alterations in human cancer. Apoptosis 9: 667-676, 2004.

5. Obenauf AC, Zou Y, Ji AL, Vanharanta S, Shu W, Shi H, Kong X, Bosenberg MC, Wiesner T, Rosen N, et al: Therapy-induced tumour secretomes promote resistance and tumour progression. Nature 520: 368-372, 2015.

6. Cai Y, Tan X, Liu J, Shen Y, Wu D, Ren M, Huang P and $\mathrm{Yu}$ D: Inhibition of PI3K/Akt/mTOR signaling pathway enhances the sensitivity of the SKOV3/DDP ovarian cancer cell line to cisplatin in vitro. Chin J Cancer Res 26: 564-572, 2014.

7. Xie X, Tang B, Zhou J, Gao Q and Zhang P: Inhibition of the PI3K/Akt pathway increases the chemosensitivity of gastric cancer to vincristine. Oncol Rep 30: 773-782, 2013.

8. Eng C: PTEN: One gene, many syndromes. Hum Mutat 22: 183-198, 2003.

9. Chalhoub $\mathrm{N}$ and Baker SJ: PTEN and the PI3-kinase pathway in cancer. Annu Rev Pathol 4: 127-150, 2009.

10. Fine B, Hodakoski C, Koujak S, Su T, Saal LH, Maurer M, Hopkins B, Keniry M, Sulis ML, Mense S, et al: Activation of the PI3K pathway in cancer through inhibition of PTEN by exchange factor P-REX2a. Science 325: 1261-1265, 2009.

11. Leslie NR: P-REX2a driving tumorigenesis by PTEN inhibition. Sci Signal 2: pe68, 2009.

12. Yu HG, Ai YW, Yu LL, Zhou XD, Liu J, Li JH, Xu XM, Liu S, Chen J, Liu F, et al: Phosphoinositide 3-kinase/Akt pathway plays an important role in chemoresistance of gastric cancer cells against etoposide and doxorubicin induced cell death. Int J Cancer 122: 433-443, 2008.

13. Fu XQ, Yu JP, Luo HS and Yu HG: The expression and role of PTEN in doxorubicin induced gastric cancer cell apoptosis. Zhonghua Nei Ke Za Zhi 49: 422-425, 2010 (In Chinese).

14. Schmidt N, Peitz U, Lippert H and Malfertheiner P: Missing gastric cancer in dyspepsia. Aliment Pharmacol Ther 21: 813-820, 2005.

15. Noh SH, Park SR, Yang HK, Chung HC, Chung IJ, Kim SW, Kim HH, Choi JH, Kim HK, Yu W, et al: Adjuvant capecitabine plus oxaliplatin for gastric cancer after D2 gastrectomy (CLASSIC): 5-year follow-up of an open-label, randomised phase 3 trial. Lancet Oncol 15: 1389-1396, 2014.

16. Yu BQ and Xie JW: Identifying therapeutic targets in gastric cancer: The current status and future direction. Acta Biochim Biophys Sin (Shanghai) 48: 90-96, 2016.

17. Ai YW, Yu HG, Yu JP, Yang Y, Li H, Hu XW and Luo HS: Impact of $\mathrm{PI} 3 \mathrm{~K} / \mathrm{Akt} / \mathrm{mdm} 2$ signaling pathway on the sensitivity of gastric cancer cell line SGC7901 to doxorubicin. Zhonghua Zhong Liu Za Zhi 30: 494-497, 2008 (In Chinese).

18. Hu Y, Guo R, Wei J, Zhou Y, Ji W, Liu J, Zhi X and Zhang J: Effects of PI3K inhibitor NVP-BKM120 on overcoming drug resistance and eliminating cancer stem cells in human breast cancer cells. Cell Death Dis 6: e2020, 2015.

19. Smolensky D, Rathore K and Cekanova M: Phosphatidylinositol3-kinase inhibitor induces chemosensitivity to a novel derivative of doxorubicin, AD198 chemotherapy in human bladder cancer cells in vitro. BMC Cancer 15: 927, 2015.

20. Wang Z, Yang L, Xia Y, Guo C and Kong L: Icariin enhances cytotoxicity of doxorubicin in human multidrug-resistant osteosarcoma cells by inhibition of $\mathrm{ABCB} 1$ and down-regulation of the PI3K/Akt pathway. Biol Pharm Bull 38: 277-284, 2015. 
21. Donald S, Hill K, Lecureuil C, Barnouin R, Krugmann S, John Coadwell W, Andrews SR, Walker SA, Hawkins PT, Stephens LR and Welch HC: P-Rex2, a new guanine-nucleotide exchange factor for Rac. FEBS Lett 572: 172-176, 2004.

22. Guo B, Liu L, Yao J, Ma R, Chang D, Li Z, Song T and Huang C: miR-338-3p suppresses gastric cancer progression through a PTEN-AKT axis by targeting P-REX2a. Mol Cancer Res 12: 313-321, 2014

23. Goler-Baron V, Sladkevich I and Assaraf YG: Inhibition of the PI3K-Akt signaling pathway disrupts ABCG2-rich extracellular vesicles and overcomes multidrug resistance in breast cancer cells. Biochem Pharmacol 83: 1340-1348, 2012.

24. Fan QW and Weiss WA: Targeting the RTK-PI3K-mTOR axis in malignant glioma: overcoming resistance. Curr Top Microbiol Immunol 347: 279-296, 2010.
25. Rasul A, Khan M, Yu B, Ali M, Bo YJ, Yang H and Ma T: Isoalantolactone, a sesquiterpene lactone, induces apoptosis in SGC-7901 cells via mitochondrial and phosphatidylinositol kinase/Akt signaling pathways. Arch Pharm Res 36: 1262-1269, 2013. 